Reprinted from $J$. Food Scl.

62(4): 889-893 \& 905

(-1997 Institute of Food Technologists

\title{
Optimizing Acceptability of Chicken Nuggets Containing Fermented Cowpea and Peanut Flours
}

\author{
W. PRINYAWIWATKUL, K. H. MCWATTERS, L. R. BEUCHAT, and R. D. PHILLIPS
}

\begin{abstract}
A mixture design was used to optimize the sensory acceptability (appearance, color, flavor, texture, and overall liking) of chicken nuggets containing flours processed from fermented cowpeas (FCF) and fermented partially defatted peanuts (FPDPF). Flavor and texture acceptability correlated highly with overall liking of nuggets. Products containing $20 \% \mathrm{FCF}$ or FPDPF alone or in combination were unacceptable. Nuggets containing a mixture of $2.5 \%$ FCF and $2.5 \%$ FPDPF were as acceptable as the control, with a sweet, chickeny flavor. This suggests market potential for such poultry products.
\end{abstract}

Key Words: consumer acceptability, sensory, cowpea, peanut, chicken nuggets

\section{INTRODUCTION}

EXTENSION OF MEAT PRODUCTS with legume and oilseed derivatives has the potential to reduce product cost (McWatters, 1990), while maintaining nutritional and sensory qualities. Soybean proteins are predominant additives for use as fillers, binders, and extenders in meat systems (Ray et al., 1981; Miles et al., 1984). Nonmeat protein additives derived from cowpeas and peanuts are less common. Partial replacement of meat with cowpea and peanut proteins has been reported (McWatters, 1977; Torgersen and Toledo, 1977; Joseph et al., 1978; Cross and Nichols, 1979; McWatters and Heaton, 1979; Perkins and Toledo, 1982; Beuchat et al., 1992).

Modification of cowpea and peanut proteins, using solid-state fermentation with Rhizopus microsporus var. oligosporus (tempeh mold), to further improve functional and nutritional qualities has been reported (Prinyawiwatkul et al., 1993a, 1997). Flours from fermented cowpeas (FCF) and fermented partially defatted peanuts (FPDPF) contain high levels of protein $(28.5 \%$ and $37 \%$, respectively) (Prinyawiwatkul et al., 1993a, 1996a) and are sources of nutrients and potential functional ingredients for a wide range of food products (Prinyawiwatkul et al., 1993b, 1996b). The fat and water binding and heat-induced gelation properties of FCF and FPDPF flours (Prinyawiwatkul et al., 1997) should be advantageous in comminuted meat systems. These flours have been successfully incorporated up to $20 \%$ in a chicken nugget formulation. Partial replacement of chicken meat with FCF or FPDPF, or their combination, affected physico-chemical and sensory characteristics of nuggets, depending on the level of addition (Prinyawiwatkul et al., 1997).

Consumer-oriented product optimization applies consumer evaluation at an early stage of product development (Fishken, 1983). Product optimization studies involve multiple formulations (Moskowitz, 1994), and various approaches may be used to identify the range of optimal formulations and sensory qualities that are critical to acceptance. Information on consumer acceptance, preference, and attitudes toward extended chicken nuggets is needed. Such prototype product should be acceptable

Authors McWatters, Beuchat, and Phillips are with the Center for Food Safety \& Quality Enhancement, Dept. of Food Science \& Technology, Univ. of Georgia, Griffin, GA 30223-1797. Author Prinyawiwatkul's current address: Dept. of Food Science, Louisiana Agricultural Experiment Station, Louisiana State Univ., Baton Rouge, LA 70803-4200. Direct inquiries to Dr. K.H. McWatters.
Table 1-Composition of extended chicken nugget formulations in a threecomponent constrained simplex lattice mixture design evaluated for acceptability of sensory qualities ${ }^{a}$

\begin{tabular}{cccc}
\hline \multirow{2}{*}{$\begin{array}{c}\text { Formulation } \\
\text { number }\end{array}$} & \multicolumn{3}{c}{ Ingredient $(\%)$} \\
\cline { 2 - 4 } & Chicken $\left(\mathrm{X}_{1}\right)$ & FCF $\left(\mathrm{X}_{2}\right)$ & FPDPF $\left(\mathrm{X}_{3}\right)$ \\
\hline 1 & 100.0 & $-\mathrm{c}$ & - \\
2 & 90.0 & 10.0 & - \\
3 & 80.0 & 20.0 & 10.0 \\
4 & 80.0 & 10.0 & 20.0 \\
5 & 80.0 & - & 10.0 \\
6 & 90.0 & - & 6.5 \\
7 & 87.0 & 6.5 & 2.5 \\
8 & 95.0 & 2.5 & 2.5 \\
9 & 82.5 & 15.0 & 15.0 \\
\hline 10 & 82.5 & 2.5 & \\
\hline
\end{tabular}

a FCF = flour processed from fermented cowpeas; FPDPF $=$ flour processed from fermented partially defatted peanuts. The chicken-FCF-FPDPF component $100 \%$ in mixture design) was $84 \%$ of the actual formulations. All formulations contained $1 \%$ sait. $0.6 \%$ garlic, $0.4 \%$ pepper, and $14 \%$ added water for a total of $100 \%$.

b formulation numbers correspond to the numbers shown in Fig. 1.

c Dash represents zero percent of the mixture.

to a targeted population (Prinyawiwatkul et al., 1993b). The objective of this study was to optimize the sensory acceptability of prototype chicken nuggets extended with flours from fermented cowpeas and/or fermented partially defatted peanuts.

\section{MATERIALS \& METHODS}

Flour and chicken nugget preparation

Mature, dry cowpeas (cv. White Acre, Southern Frozen Foods, Montezuma, GA) and peanuts (cv. Florunner, McClesky Mills, Smithville, GA) were obtained. Food-grade flours processed from fermented cowpeas (FCF) and fermented partially defatted peanuts (FPDPF) were prepared under sanitary conditions (Prinyawiwatkul et al., 1993a, 1996a). The commercial dried powder starter culture of Rhizopus microsporus var. oligosporus (tempeh mold) was purchased from Tempeh Lab, Inc., Summertown, TN. Fermentation times were: cowpeas, $21 \mathrm{hr}$ and peanuts, $22 \mathrm{hr}$.

Boneless, skinless chicken breasts (Continental Grain Co., Pendergrass, GA) were trimmed of external fat and visible connective tissue and coarsely ground in a chopper (Model 5120-0-009, Toledo Scale Co., Toledo, $\mathrm{OH}$ ) equipped with a 9.5 -mm-opening disc. Flours (FCF and FPDPF) and seasonings (garlic powder, salt, and black pepper) were weighed and added to the formulations (Table 1, Fig. 1). They were hydrated with tap water and thoroughly mixed with ground chicken in a mixer (Model N-50G, Hobart Mfg. Co., Troy, OH) equipped with a flat beater and operated at a low speed (\#1) for 2 min. The chicken mixture was transferred to a food cutter (Model 84142, Hobart Mfg. Co., Troy, $\mathrm{OH}$ ) and chopped for $30 \mathrm{sec}$ to provide a uniform blend. The mixture from each formulation was weighed to provide individual nugget pieces $(25 \pm 1 \mathrm{~g}$ per piece), shaped into discs about $1.5-\mathrm{cm}$ thick, and deep-fat fried in soybean oil at $193^{\circ} \mathrm{C}$ for 2 min using a Wells automatic fryer (Model F-48, Wells Mfg. Co., San Francisco, CA). Fried nuggets were drained on absorbent paper, kept warm by covering with aluminum foil, and served to consumers within $30 \mathrm{~min}$ for acceptability evaluation.

\section{Experimental design}

A three-component constrained simplex lattice mixture design (Cornell, 1983) was used. The mixture components consisted of chicken $\left(X_{1}\right)$ flour from fermented cowpeas (FCF, $\mathrm{X}_{2}$ ), and flour from fermented partially defatted peanuts (FPDPF, $\mathrm{X}_{3}$ ), which made up $84 \%$ of the total formulation. All formulations contained $1 \%$ salt, $0.6 \%$ garlic powder, 


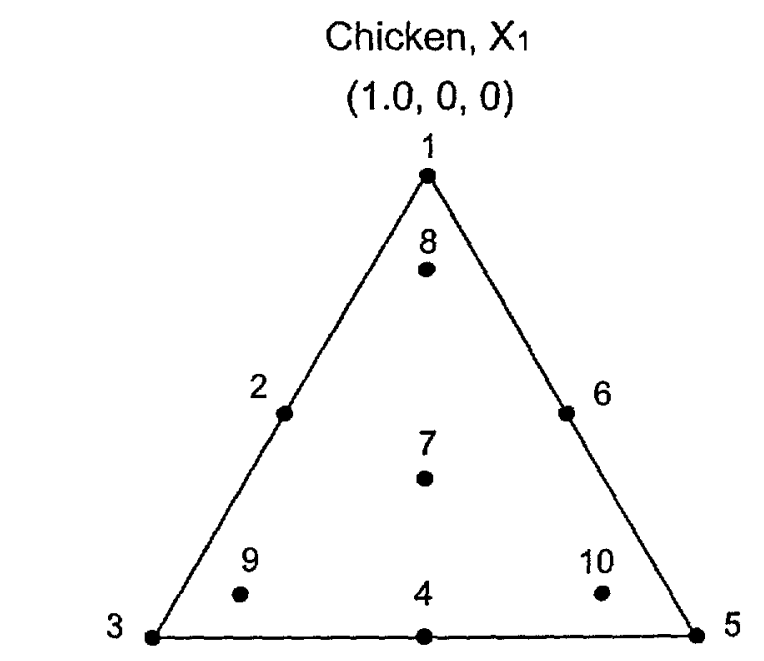

$\begin{array}{cc}\text { FCF }, X_{2} & \text { FPDPF, } X_{3} \\ (0.8,0.2,0) & (0.8,0,0.2)\end{array}$

Fig. 1-Constrained region in the simplex coordinate system defined by the following restrictions: $0.8 \leq X_{1} \leq 1.0,0.0 \leq X_{2} \leq 0.2$, and $0.0 \leq X_{3} \leq \mathbf{0 . 2}$. Numbers (1-10) represent ten formulations and correspond to the numbers in Table 1.

$0.4 \%$ black pepper, and $14 \%$ added water. Component proportions were expressed as fractions of the mixture and the sum $\left(X_{1}+X_{2}+X_{3}\right)$ of the proportions equaled 1.0. The practical range of proportions of component variables $\left(X_{1}, X_{2}\right.$, and $\left.X_{3}\right)$ was established (Fig. I and Table 1 ) based on preliminary work. Ten mixtures were tested.

\section{Consumer acceptance test}

Untrained consumers ( $n=60$ ) were randomly recruited from the Griffin, GA area. Criteria for recruitment were that they were: (1) between 18 and 65 years of age, (2) not allergic to chicken, peas, peanuts, soybean oil, garlic powder, salt, and black pepper, (3) regular consumers of fried chicken products such as chicken fingers, patties, nuggets, or similar products, and consumed such products at least once a week, and (4) available and willing to participate on specific testing dates. Because most of the testers had not participated in consumer acceptance tests, they were briefly instructed on the testing procedures, particularly use of the consumer ballot. Consumers were asked to provide socioeconomic and demographic information including age, sex, race, marital status, educational level, employment status, household income, and frequency of eating meals away from home. They also provided information on consumption of fried chicken products, i.e., fingers, patties, nuggets or the like, including degree of liking, consumption frequency, expenditures for such products, the most critical quality attribute and taste preference of such products, and nutrition. Tests were conducted in partitioned booths in a sensory laboratory; each booth was illuminated with two 50 watt indoor reflector flood lights. The test room was temperature controlled and free of environmental elements that might interfere with normal perceptions. A total of 6 consumer test sessions were conducted from 10:30-11:30 a.m., 2:30-3:30 p.m., and 5:30-6:30 p.m. during a 2-day period.

A balanced incomplete block design (Plan 11.16, $t=10, k=4, r=$ $6, \mathrm{~b}=15, \lambda=2, \mathrm{E}=0.83$, type III) described by Cochran and Cox (1957) was used because an individual consumer would find it increasingly difficult to evaluate a product as the number of samples increased. This design allowed each consumer to evaluate four samples out of 10 . Each pair of samples was compared two times. With two replications each of the 10 experimental formulations was evaluated 48 times (48 consumer responses). Only 45 responses per formulation were used for final analyses due to incomplete ballots. This number would provide dependable, reliable results that could be used to generate models relating sensory qualities and acceptability (Moskowitz, 1994).

Freshly prepared nuggets were presented (1 piece per formulation) to consumers in $59-\mathrm{mL}$ white plastic cups coded with three-digit random numbers on a tray lined with white paper. Water and expectoration cups were provided for consumers to use during the test to minimize any residual effect between samples. Consumers were asked to evaluate two sets (replications) of samples with a 5-min break after the first set. They were instructed to chew at least one-half of the nugget before evaluating acceptability of the appearance, color, flavor, texture/mouthfeel, and overall liking (acceptance) of each product using a 9-point hedonic scale $(1=$ dislike extremely, $5=$ neither dislike nor like, and $9=$ like extremely) (Peryam and Pilgrim, 1957). As noted by Schutz (1983), consumers are typically asked to give judgments on how much they like or dislike products and not asked to provide reasons for their decisions. In our study, however, consumers were instructed to comment freely about the products directly on the ballot. Consumers' verbal comments after having completed the sensory evaluation were also recorded. An incentive ( $\$ 10$ honorarium) was given to all consumers for participating in the study.

\section{Statistical and data analyses}

Multiple regression analysis (Proc Reg, SAS Institute, Inc., 1988) was used to fit a quadratic canonical polynomial model described by Scheffé (1958) as follows:

$$
Y=\beta_{1} X_{1}+\beta_{2} X_{2}+\beta_{3} X_{3}+\beta_{12} X_{1} X_{2}+\beta_{13} X_{1} X_{3}+\beta_{23} X_{2} X_{3}
$$

where $Y=$ a predicted dependent variable (either appearance, color, flavor, texture acceptability or overall liking), $\beta_{1}, \beta_{2}, \beta_{3}, \beta_{12}, \beta_{13}, \beta_{23}=$ corresponding parameter estimates for each linear and cross product term, $X_{1}=$ chicken, $X_{2}=F C F$, and $X_{3}=$ FPDPF. Because of the restriction of the mixture design $\left(X_{1}+X_{2}+X_{3}=1.0\right)$, it was not possible to estimate the intercept $\left(\beta_{0}\right)$ and all linear coefficients $(\beta i)$. The regression model was not full rank. The intercept and parameters such as $X_{1} X_{1}$, $X_{2} X_{2}$, and $X_{3} X_{3}$ were set to zero and thus not included in the models. Adjusted $R^{2}$ was also redefined. Selection of variables was systematically performed based on prob $>|\mathrm{T}|$ at a $0.1-0.15$ level $(\mathrm{Ho}: \mathrm{Bi}=0$ ) (Schutz, 1983 ) and adjusted $R^{2}$ values to finalize and provide reduced models for prediction of acceptability of each sensory attribute and overall liking. Analysis of variance (ANOVA) was performed to determine differences in acceptability for each sensory attribute and overall liking among nugget samples. Tukey's studentized range test was performed for post-hoc multiple comparisons.

\section{Deriving the optimum formulation}

Predictive models were used to generate contour plots for appearance, color, flavor, texture acceptability, and overall liking. Based on previous knowledge of processing practicality (Prinyawiwatkul et al., 1997) and sensory acceptability of the products, acceptable areas were arbitrarily defined as those which were predicted to result in consumer ratings $>5.4$ (on a 9-point hedonic scale) on the contour plots. The optimum area determined by superimposing acceptable areas (Palomar et al., 1994) represented all combinations of mixtures that would meet pre-set criteria for an acceptable prototype product.

\section{RESULTS \& DISCUSSION}

\section{Consumer characteristics}

The consumers were female (49) and male (11) and they were white $(90 \%)$, Asian (7\%), and African-American (3\%). The majority $(80 \%)$ was well distributed among the ages of $18-44$. The remainder were $45-64$ years of age $(15 \%)$ and over 64 years of age $(5 \%)$. Their status was single $(28 \%)$, married $(58 \%)$, and divorced or separated $(8 \%)$. Some had completed high school (22), some had less than 4 years of college (16), and the rest held a college degree (19). They were full-time employees $(35 \%)$, part-time employees (30\%), homemakers ( $22 \%)$, and students $(15 \%)$. Over half of the consumers $(58 \%)$ had an annual income of $\$ 30,000$ to $\$ 70,000$ and $20 \%$ earned $\$ 10,000$ to $\$ 30,000$. Note that although the consumers were not representative of the U.S. population, they represented regular consumers of fried chicken products.

More than half $(63 \%)$ of the consumers indicated that they ate out twice a week, $20 \%$ seven times a week, and $10 \%$ once a week. Most of them (92\%) liked (moderately to extremely) to consume fried chicken products such as chicken fingers, patties, nuggets, or similar products. About half indicated that they consumed such products at least once a week and spent about $\$ 4-10 /$ wk for them. Consumers (75\%) ranked 'taste' as the most 
critical sensory attribute, followed by aroma/odor and then color. Texture or nutrition was not listed as an important attribute for this type of product. Products with 'salty' or 'hot-spicy' flavor or their combination were much more preferred than products with 'sweet' or 'mild' flavor. Eleven consumers believed that fried chicken products (fingers, patties, nuggets and the like) have high to very high nutritive value, 27 consumers indicated moderate nutritive value, and 19 indicated low to very low nutritive value.

\section{Consumer acceptability}

Appearance and color. Appearance includes sensory attributes such as color, shape, and size as well as more complex attributes such as surface texture and structural uniformity (MacDougall, 1983; Cardello, 1994). Mean scores for acceptability of appearance and color of nuggets (Table 2, Fig. 2) were influenced by the presence of FCF and FPDPF in the formulations. Appearance and color scores for all nuggets were $>5.0$ (neither like nor dislike, Table 2). Of 45 responses per formulation, $>77 \%$ (data not shown) rated appearance and color of all nuggets (except those with $20 \% \mathrm{FCF}$ ) as "like slightly to like extremely." Appearance and color scores for extended nuggets (excluding those containing 20\% FCF) ranged from 6.4 (like slightly) to 7.3 (like moderately) and from 6.7 to 7.4 (like moderately). At $10 \%$ addition, appearance and color scores of nuggets extended with FCF were not different from those extended with FPDPF (Table 2).

Addition of FCF and/or FPDPF to nugget formulations up to $20 \%$ generally decreased appearance acceptability as compared to the control (Table 2, Fig. 2) but appearance was not unacceptable. As noted by Cardello et al. (1983), both color and particle size of protein ingredients affect visual and textural appearance of extended patties. The lowest appearance (5.4) and color (6.1) scores were observed for nuggets containing $20 \%$ FCF. Although FCF particles were uniformly dispersed and suitably small to allow good binding of water, fat, and chicken pieces during nugget preparation, particles were large enough to be discernible at the surface and in the interior of nuggets (Prinyawiwatkul et al., 1997). Visual observation indicated that nuggets containing $20 \% \mathrm{FCF}$ had a smoother outer surface and less shrinkage than the control or those containing the same level of FPDPF. The smooth surface of nuggets was not a characteristic expected by consumers. Shrinkage and an unsmooth surface of control nuggets after frying did not cause the appearance to be unacceptable (mean score 6.8, like moderately).

FCF and FPDPF flours ranged from light yellow to light brown (Prinyawiwatkul et al., 1993a, 1996a). These colors may or may not cause undesirable effects in chicken nuggets depending on addition level. Only slight differences in total color $(\Delta E)$ were observed as the amount of FCF in nuggets was increased from $10 \%(\Delta E=13.8)$ to $20 \%(\Delta E=13.5)$ (Prinyawiwatkul et al., 1997). However, these differences were evidently discerned by consumers as shown by differences in color scores ( 7.4 vs 6.1). Quality of the nuggets may have been first judged according to color based on expectations. The lower color score of nuggets containing $20 \%$ FCF as compared to the control (Fig. 2) may have been due to the intense brown color. The lower acceptability score may be associated with disconfirmed consumer expectations (Cardello, 1994) with regard to typical color of fried chicken nuggets. Nuggets extended with $10 \%$ FCF or $10 \%$ FPDPF or a mixture of $2.5 \%$ FCF and 15\% FPDPF received higher color scores than the control. Consumers described the color of nuggets containing $10 \%$ FCF or FPDPF as golden brown, which is a typical and desirable color for fried chicken products.

Flavor. The mean score for flavor acceptability of control nuggets was 6.5 ; flavor was adversely affected by addition of FCF and FPDPF (Table 2). Of 60 consumers, $71-73 \%$ disliked (slightly to extremely) the flavor of nuggets containing $20 \%$ FCF or $20 \%$ FPDPF (data not shown). More than $55 \%$ of the consumers, however, liked (slightly to very much) the nuggets
Table 2-Mean consumer scores for acceptability of appearance, color, flavor, texture/mouthfeel, and overall liking of chicken nuggets extended with cowpea and peanut flours ${ }^{a}$

\begin{tabular}{|c|c|c|c|c|c|}
\hline \multirow[b]{2}{*}{$\begin{array}{c}\text { Formulation } \\
\text { number }\end{array}$} & \multicolumn{5}{|c|}{ Acceptability mean score } \\
\hline & $\begin{array}{l}\text { Appear- } \\
\text { ance }\end{array}$ & Color & Flavor & Texture & $\begin{array}{l}\text { Overall } \\
\text { liking }\end{array}$ \\
\hline 1 & $\begin{array}{c}6.8 \mathrm{a} \\
|1.6\rangle\end{array}$ & $\begin{array}{l}6.7 \mathrm{ab} \\
(1.5)\end{array}$ & $\begin{array}{l}6.5 \mathrm{a} \\
\{1.4\}\end{array}$ & $\begin{array}{l}6.4 \mathrm{ab} \\
\langle 1.5\rangle\end{array}$ & $\begin{array}{l}6.5 \mathrm{a} \\
(1.4)\end{array}$ \\
\hline 2 & $\begin{array}{l}7.3 \mathrm{a} \\
(1.1)\end{array}$ & $\begin{array}{l}7.4 \mathrm{a} \\
(1.1)\end{array}$ & $\begin{array}{l}5.6 \mathrm{ab} \\
(1.9)\end{array}$ & $\begin{array}{l}5.2 \text { bcde } \\
(2.1)\end{array}$ & $\begin{array}{l}5.4 \mathrm{abc} \\
(2.0)\end{array}$ \\
\hline 3 & $\begin{array}{l}5.4 \mathrm{~b} \\
(1.9)\end{array}$ & $\begin{array}{l}6.1 \mathrm{~b} \\
\langle 1.8\rangle\end{array}$ & $\begin{array}{l}3.8 \mathrm{e} \\
\langle 1.9\rangle\end{array}$ & $\begin{array}{l}3.2 f \\
(1.6)\end{array}$ & $\begin{array}{l}3.6 \mathrm{f} \\
(1.8)\end{array}$ \\
\hline 4 & $\begin{array}{l}6.7 \mathrm{a} \\
(1.6)\end{array}$ & $\begin{array}{l}7.0 \mathrm{a} \\
(1.3)\end{array}$ & $\begin{array}{l}4.2 \text { de } \\
(1.9)\end{array}$ & $\begin{array}{l}4.5 \mathrm{de} \\
(1.8)\end{array}$ & $\begin{array}{l}4.1 \text { def } \\
(1.9)\end{array}$ \\
\hline 5 & $\begin{array}{l}6.4 \mathrm{ab} \\
(1.8)\end{array}$ & $\begin{array}{l}6.8 \mathrm{ab} \\
(1.5)\end{array}$ & $\begin{array}{l}4.0 \text { de } \\
(1.6)\end{array}$ & $\begin{array}{l}4.7 \text { cde } \\
(2.1)\end{array}$ & $\begin{array}{l}4.3 \text { cdef } \\
(1.6)\end{array}$ \\
\hline 6 & $\begin{array}{l}7.0 \mathrm{a} \\
(1.1)\end{array}$ & $\begin{array}{l}7.2 \mathrm{a} \\
(1.0)\end{array}$ & $\begin{array}{l}5.5 \mathrm{abc} \\
\{1.5\}\end{array}$ & $\begin{array}{l}5.9 \mathrm{abc} \\
(1.6)\end{array}$ & $\begin{array}{l}5.6 \mathrm{ab} \\
\langle 1.7\rangle\end{array}$ \\
\hline 7 & $\begin{array}{c}6.7 \mathrm{a} \\
\langle 1.4\rangle\end{array}$ & $\begin{array}{l}6.8 \mathrm{ab} \\
(1.5)\end{array}$ & $\begin{array}{l}5.1 \mathrm{bcd} \\
(1.8)\end{array}$ & $\begin{array}{l}5.3 \text { bcde } \\
(1.9)\end{array}$ & $\begin{array}{l}5.2 \text { bcde } \\
(1.8)\end{array}$ \\
\hline 8 & $\begin{array}{l}6.9 \mathrm{a} \\
(1.3)\end{array}$ & $\begin{array}{l}6.8 \mathrm{ab} \\
(1.4)\end{array}$ & $\begin{array}{l}6.0 \mathrm{ab} \\
(1.8)\end{array}$ & $\begin{array}{c}6.5 \mathrm{a} \\
(1.5)\end{array}$ & $\begin{array}{l}6.2 \text { ab } \\
(1.6)\end{array}$ \\
\hline 9 & $\begin{array}{l}6.4 \mathrm{àb} \\
(1.6)\end{array}$ & $\begin{array}{l}6.7 \mathrm{ab} \\
\langle 1.3\rangle\end{array}$ & $\begin{array}{l}4.3 \mathrm{cde} \\
\text { (1.9) }\end{array}$ & $\begin{array}{l}4.2 \text { ef } \\
(2.1)\end{array}$ & $\begin{array}{l}4.1 \text { ef } \\
(2.0)\end{array}$ \\
\hline 10 & $\begin{array}{c}6.9 \mathrm{a} \\
(1.6)\end{array}$ & $\begin{array}{c}7.3 \mathrm{a} \\
(1.1)\end{array}$ & $\begin{array}{l}5.0 \mathrm{bcd} \\
(1.9)\end{array}$ & $\begin{array}{l}5.6 \text { abcd } \\
(1.8) \\
\end{array}$ & $\begin{array}{l}5.3 \mathrm{bcd} \\
(1.9)\end{array}$ \\
\hline Range & 1.9 & 1.3 & 2.7 & 3.3 & 2.9 \\
\hline
\end{tabular}

a Numbers in parentheses refer to standard deviation of 45 consumer responses. A 9 point hedonic scale was used $11=$ dislike extremely, $5=$ neither like nor dislike, and 9 = like extremely). Mean values in the same column not followed by the same letter are significantly different $(p \leq 0.05)$. Range values were calculated as the differences between the highest and lowest mean scores for each sensory attribute.

b Formulation numbers correspond to the numbers shown in Fig. 1 and Table 1.

extended with $10 \%$ FCF or $10 \%$ FPDPF or a mixture of $2.5 \%$ FCF and $2.5 \%$ FPDPF. The contour plot (Fig. 2) generated by the equation (Table 3 ) revealed that flavor acceptability of nuggets generally decreased with increased amounts of FCF and FPDPF in the formulations. Among extended products, the flavor of nuggets extended with a mixture of $2.5 \% \mathrm{FCF}$ and $2.5 \%$ FPDPF (formulation \#8) was most acceptable (score $=6.0$ ). That product was characterized as having a sweet, chickeny flavor similar to control nuggets (Prinyawiwatkul et al., 1997). Addition of $10 \%$ FCF or FPDPF to formulations lowered the flavor score from 6.5 to 5.6 or 5.5 . Addition of $20 \% \mathrm{FCF}$ or FPDPF caused the flavor of nuggets to become unacceptable (score $\leq 4.0$ ). Consumers described the flavor of nuggets extended with $20 \%$ FPDPF as 'hay-like', 'peanut-shell' and 'sour' whereas those with $20 \%$ FCF were described as 'mild', 'bland' or 'tasteless.' The hay-like and unusual sour flavors were objectionable to consumers.

Texture. The predicted texture acceptability scores (Fig. 2), although not highly accurate $\left(\mathrm{R}^{2}\right.$-adjusted $=0.68$, Table 3$)$, could give an estimate of how much FCF and FPDPF may be added to nugget formulations without causing texture to become unacceptable. The ability of FCF and FPDPF to bind water, fat, and chicken pieces during preparation and frying is the key factor affecting textural quality (Prinyawiwatkul et al., 1997). The texture of nuggets containing a mixture of $2.5 \% \mathrm{FCF}$ and $2.5 \%$ FPDPF was as acceptable as the control (score 6.5 vs. 6.4, Table 2 ); $\approx 27 \%$ of the consumers rated texture as 'like slightly', $20 \%$ as like 'moderately', $\approx 31 \%$ as 'like very much', and $2 \%$ as 'like extremely' (data not shown). Addition of $10 \%$ FCF or FPDPF decreased texture acceptability scores as compared to controls but the texture remained acceptable. The texture of nuggets containing $10 \%$ FPDPF was more acceptable (score $=5.9$ ) than nuggets containing 10\% FCF (score = 5.2). Regardless of type of flour, addition of $20 \%$ caused product texture to be unacceptable. The least acceptable texture was observed in nuggets containing $20 \%$ FCF (mean score 3.2 ) where $>85 \%$ of consumers disliked (slightly to extremely) the texture of this product The tough and dry texture (high Warner Bratzler peak force and energy to shear) of nuggets extended with $20 \%$ FCF was attributed to the available water (from added water and chicken meat) in the nuggets and water binding properties of FCF proteins and 


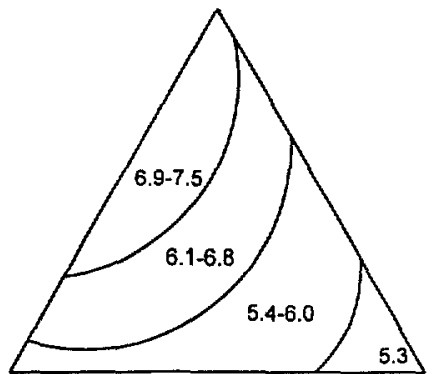

Appearance

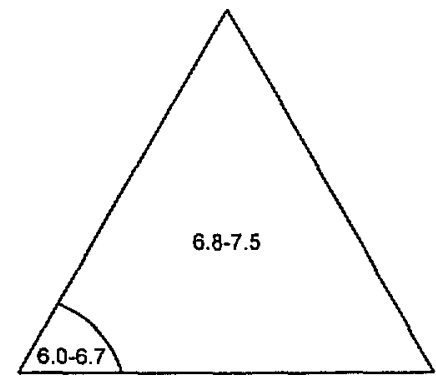

Color

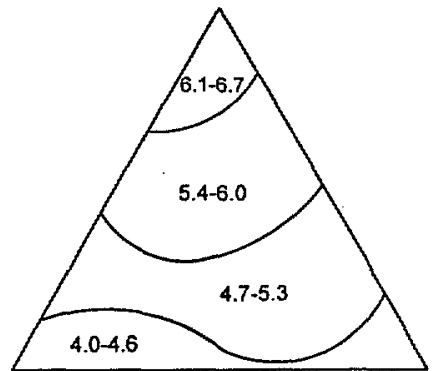

Flavor

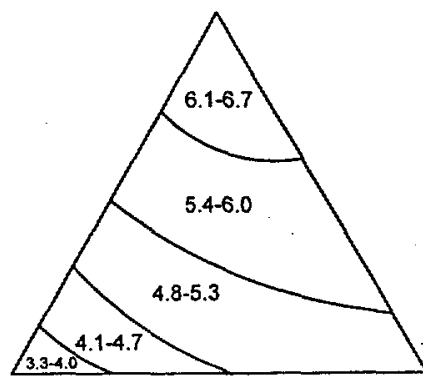

Texture

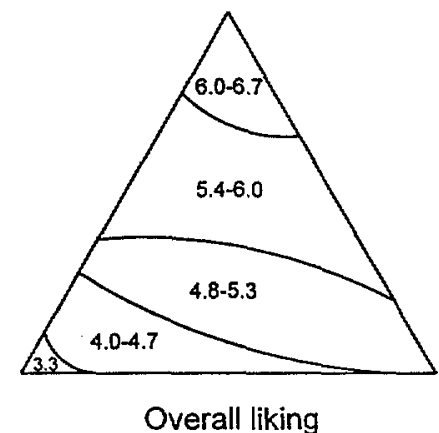

Fig. 2-Contour plots for predicted acceptability values of appearance, color, flavor, texture and overall liking. See Fig. 1 for coordinate points $\left(X_{1}, X_{2}, X_{3}\right)$ and formulation numbers.

Table 3-Reduced quadratic canonical polynomials for each of dependent sensory attributes and overall liking of chicken nuggets containing proportions of chicken $\left(X_{1}\right)$, cowpea flour $\left(F C F, X_{2}\right.$ ), and peanut flour (FPDPF. $\left.\mathrm{X}_{3}\right)^{\mathrm{a}}$

\begin{tabular}{|c|c|c|}
\hline $\begin{array}{l}\text { Dependent } \\
\text { variable }\end{array}$ & Predictive model & $\begin{array}{c}\mathrm{R}^{2}- \\
\text { adjusted }\end{array}$ \\
\hline $\begin{array}{l}\text { Appearance } \\
\text { accept- } \\
\text { ability } \\
\text { Color }\end{array}$ & $6.84 X_{1}-77.11 X_{2}+5.5 X_{3}+96.14 X_{1} X_{2}+60.5 X_{2} X_{3}$ & 0.87 \\
\hline $\begin{array}{l}\text { accept- } \\
\text { ability } \\
\text { Flavor }\end{array}$ & $6.74 X_{1}-59.68 X_{2}+8.01 X_{3}+78.99 X_{1} X_{2}+42.64 X_{2} X_{3}$ & 0.92 \\
\hline $\begin{array}{l}\text { accept- } \\
\text { ability } \\
\text { Texture }\end{array}$ & $6.52 X_{1}-43.96 X_{2}-4.79 X_{3}+45.54 X_{1} X_{2}+30.4 X_{2} X_{3}$ & 0.71 \\
\hline $\begin{array}{l}\text { accept- } \\
\text { ability } \\
\text { Overall }\end{array}$ & $6.65 X_{1}-44.17 X_{2}-1.55 X_{3}+41.71 X_{1} X_{2}+52.45 X_{2} X_{3}$ & 0.68 \\
\hline liking & $6.46 X_{1}-35.55 X_{2}-22.24 X_{3}+34.55 X_{1} X_{2}+23.93 X_{1} X_{3}$ & 0.70 \\
\hline
\end{tabular}

a Based on 450 observations. Consumer scores were based on a 9-point hedonic scale ( 1 = dislike extremely, $5=$ neither like nor disfike, and $9=$ like extremely). $R^{2}$-adjusted $=1-\left[\left((n-i)\left(1-R^{2}\right)\right] /(n-p)\right]$, where $i=0$ for a non-intercept regression model, $n=$ the number of observations used to fit the model, and $p=$ the number of parameters in the model (SAS Institute, Inc., 1988).

carbohydrates (Prinyawiwatkul et al., 1997). The soft and tender texture (low peak force and energy to shear) of nuggets containing FPDPF was attributed to the amount of fat in the nuggets and fat binding properties of FPDPF proteins (Prinyawiwatkul et al., 1997). Consumers described the texture of nuggets extended with $20 \%$ FPDPF as moist, juicy, and tender but lacking typical chunkiness of chicken nugget products.

Overall liking. The mean score for overall liking or acceptance of control nuggets was 6.5 ; overall liking was strongly influenced by FCF and FPDPF (Table 2). The ratings for satisfaction or overall liking of a food are not only based on intrinsic sensory characteristics, but also the degree to which the product meets sensory and hedonic expectations (Cardello, 1994). For a familiar food like chicken nuggets, expectations are clear and may be readily articulated indicating consumers know what quality attributes they prefer. This is evidenced by the wide variation in overall liking scores of all nuggets which ranged from 3.6 (dislike slightly) to 6.5 (like slightly to moderately). Addition of FCF and FPDPF to nugget formulations decreased overall liking scores (Fig. 2). More than 70\% of consumers disliked (slightly to very much) nuggets containing $20 \%$ FCF (score $=3.6$ ) or $20 \%$ FPDPF (score $=4.3$ ). However, more than $50 \%$ indicated that they liked (slightly to extremely) nuggets containing $10 \%$ FCF (score $=5.4$ ) or $10 \%$ FPDPF (score $=5.6$ ). Among extended products, nuggets containing a mixture of $2.5 \%$ FCF and $2.5 \%$ FPDPF were most acceptable and compared favorably to controls. About $16 \%$ of consumers rated overall liking of this product as 'like slightly', $24.4 \%$ as 'like moderately', and $26.7 \%$ as 'like very much.'

\section{Sensory attributes influencing overall liking}

Analysis of variance (ANOVA) and post-hoc multiple comparisons (Table 2) indicated that differences existed in acceptability of appearance, color, flavor and texture as well as overall liking of the 10 formulations. Sensory attributes of a food are very important in its overall acceptance (Cardello, 1994; Love, 1994). However, not all sensory attributes are equally important (Sidel et al., 1994). The sensory attributes which best differentiate products can be identified by computing the range (differences between the highest and lowest) of ratings for any given attribute (Moskowitz, 1994). The range values (Table 2) indicated that texture acceptability (range value $=3.3$ ) differentiated products the most, followed by overall liking (2.9), flavor (2.7), appearance (1.9), and color (1.3). The range of ratings is purely descriptive and not predictive (Moskowitz, 1994).

The pattern of consumer acceptability scores for flavor and texture of all nuggets was similar to that for overall liking (Table 2). Consumers are influenced differently by specific sensory attributes when they judge overall acceptance (Moskowitz, 1994). The Pearson correlation coefficients between overall liking and acceptability of appearance, color, flavor and texture were 0.39 , $0.32,0.92$, and 0.87 , respectively. Scrutinizing results from ANOVA, post-hoc multiple comparison, range, and correlation 


\section{Chicken, $X_{1}$}

$(1.0,0,0)$

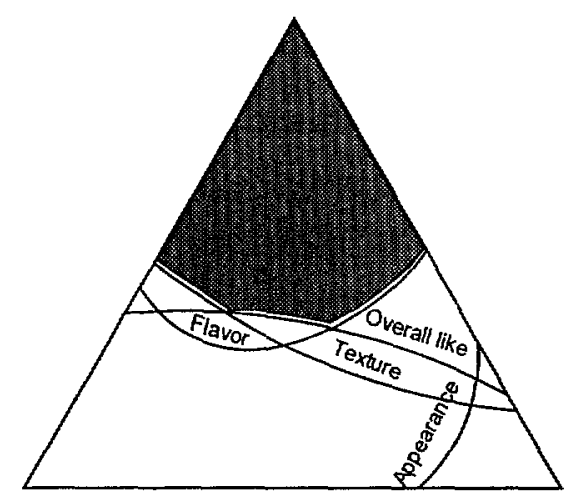

FCF, $X_{2}$

FPDPF, $X_{3}$

$(0.8,0.2,0)$

$(0.8,0,0.2)$

Fig. 3-Optimum region (shaded) of chicken $\left(X_{1}\right)$, flour from fermented cowpeas (FCF, $X_{2}$ ), and flour from fermented partially defatted peanuts (FPDPF, $X_{3}$ ) that would yield nuggets with acceptable sensory qualities (scores $\geq 5.4$ on a 9-point hedonic scale).

analyses, we concluded that flavor and texture, rather than appearance and color, most influenced overall liking of the chicken nuggets. For example, the appearance and color of nuggets containing 20\% FPDPF (formulation \#5) or a mixture of $15 \% \mathrm{FCF}$ and $2.5 \%$ FPDPF (formulation $\# 9$ ) or a mixture of $10 \% \mathrm{FCF}$ and $10 \%$ FPDPF (formulation \#4) were acceptable (score $=6.4-7.0$ ) but flavor and texture were unacceptable (score $=4.0-4.7$ ). This caused the overall liking of the products to be unacceptable (score $=4.1-4.3$, Table 2 ). Note that the ratings for overall liking may have been influenced by a "halo effect" since consumers provided responses to overall liking of nugget products following a series of questions about appearance, color, flavor, and texture. When more than one attribute of a sample is evaluated, the ratings will tend to influence each other, thus resulting in a halo effect. The design used did not permit detection of this type of influence. Initially consumers rated taste' as the most important sensory quality attribute of nuggets, whereas texture and nutrition were rated least important. No further effort was attempted to determine whether flavor of the nuggets had greater influence on overall liking than did texture, although flavor is more frequently reported as the reason for rejecting a food (Cardello, 1994).

\section{Deriving the optimum formulation}

In sensory evaluation, optimization is defined as a procedure for developing the best (most liked or most preferred) possible product in its class (Sidel and Stone, 1983). An optimal formulation should maximize consumer acceptance of a given set of ingredients (Fishken, 1983). In most applications, it would be impossible to develop a product with all desirable sensory qualities that would satisfy consumers, but it should be possible to approach that result (Moskowitz, 1994). Formulations that were rated 5.4 or higher for appearance, color, flavor, and texture acceptability, and overall liking were used to derive an optimum. Superimposing acceptable areas of contour plots revealed that flavor, texture, and overall liking were limiting factors in attaining the optimum. All formulations (shaded area, Fig. 3), containing $<10 \%$ FCF or FPDPF, either alone or in combination, were predicted to produce products with an overall liking score $\geq 5.4$. Regardless of type of flour, any formulation with $<5 \%$ added flour would yield a product with predicted acceptability scores $>6.0$ for flavor, texture, and overall liking and scores $>6.8$ for appearance and color.

\section{CONCLUSIONS}

FLOURS FROM FERMENTED COWPEAS (FCF) and fermented partially defatted peanuts (FPDPF) could be incorporated up to $10 \%$ into formulations to produce acceptable extended chicken nuggets. Flavor and texture more than appearance and color influenced overall acceptance of the nuggets. Among extended products, those containing a mixture of $2.5 \% \mathrm{FCF}$ and $2.5 \%$ FPDPF were as acceptable as controls and have market potential. Scale-up production and further sensory, consumer, and marketing research are essential to confirm the demand for this prototype product.

\section{REFERENCES}

Beuchat, L.R., Chompreeda, P., Garcia, V.V., Oupadissakoon, C., Haruthaithanasan, V., del Rosario, R.R., and Mabesa, R.C. 1992. Some new groundnut products in Southeast Asia. In Groundnut-a Global Perspective:
Proceedings of an International Workshop, S.N. Nigam (Ed.), p. 249-255. ICRISAT Center, Patancheru, India.

Cardello, A.V. 1994. Consumer expectations and their role in food acceptance. Ch.10 in Measurement of Food Preferences, H.J.H. MacFie and D.M.H. Thomson (Ed.), p. 253-297. Blackie Academic \& Professional, London, UK.

Cardello, A.V., Secrist, J., and Smith, J. 1983. Effects of soy particle size and color on the sensory properties of ground beef patties. J. Food Qual. 6: $139-151$.

Cochran, W.G. and Cox, G.M. 1957. Experimental Designs, 2nd ed. John Wiley \& Sons, New York, NY.

Cornell, J.A. 1983. How to Run Mixture Experiments for Product Quality. American Society for Quality Control, Milwaukee, WI.

Cross, H.R. and Nichols, J.E. 1979. Palatability of ground beef patties containing peanut meal, structured soy protein, and mechanically processed beef. Peanut Sci. 6: 115-118.

Fishken, D. 1983. Consumer-oriented product optimization. Food Technol. Fishken, D. 1983.

Joseph, A.L., Berry, B.W., Wells, L.H., Wagner, S.B., Maga, J.A., and Kylen, A.M. 1978. Utilization of texturized peanut grits in frankfurters. Peanut Sci. 5: $61-64$.

Love, J. 1994. Product acceptability evaluation. Ch. 13 in Advances in Meat Research: Quality Attributes and Their Measurement in Meat, Poultry and Fish Products, Vol. 9, A.M. Pearson and T.R. Dutson (Ed.), p. 337-358. Blackie Academic \& Professional, London, UK.

MacDougall, D.B. 1983. Instrumental assessment of the appearance of foods. Ch. 3.1 in Sensory Quality in Foods and Beverages: Definition, Measurement and Control, A.A. Williams and R.K.Atkin (Ed.), p. 121-139. Verlag Chemie International, Inc., FL.

MeWatters, K.H. 1977. Performance of defatted peanut, soybean and field pea meals as extenders in ground beef patties. J. Food Sci. 42: 1492-1495. McWatters, K.H. 1990. Functional characteristics of cowpea flours in foods. JAOCS. 67: 272-275.

McWatters, K.H. and Heaton, E.K. 1979. Quality characteristics of ground beef patties extended with moist-heated and unheated seed meals. JAOCS. 56: $86 \mathrm{~A}-90 \mathrm{~A}$.

Miles, C.W., Ziyad, J., Bodwell, C.E., and Steele, P.D. 1984. True and apparent retention of nutrients in hamburger patties made from beef or beef extended with three different soy proteins. J. Food Sci. 49: 1167-1170.

Moskowitz, H.R. 1994. Product optimization: approaches and applications. Ch. 5 in Measurement of Food Preferences, H.J.H. MacFie and D.M.H. Thomson (Ed.), p. 97-136. Blackie Academic \& Professional, London, UK.

Palomar, L.S., Galvez, F.C.F., Resurreccion, A.V.A., and Beuchat, L.R. 1994. Palomar, L.S., Galvez, F.C.F., Resurreccion, A.V.A., and Beuchat, L.R. 1994. u.-Technol. 27: 314-318.

Perkins, D. and Toledo, R.T. 1982. Effect of heat treatment for trypsin inhibitor inactivation on physical and functional properties of peanut protein. J. Food Sci. 47: 917-923.

Peryam, D.R. and Pilgrim, F.J. 1957. Hedonic scale method of measuring

food preferences. Food Technol. 11(9): 9-14.
Prinyawiwatkul, W., Beuchat, L.R., and McWatters, K.H. 1993a. Functional property changes in partially defatted peanut flour caused by fungal fer-
mentation and heat treatment. J. Food Sci. 58: 1318-1323.

mentation and heat treatment. J. Food Sci. 58: 1318-1323.
Prinyawiwatkul, W., Beuchat, L.R., McWatters, K.H., and Phillips, R.D. 1996a. Fermented cowpea flour: production and characterization of se1996a. Fermented cowpea flour: production and characterization of sePrinyawiwatkul, W., Beuchat, L.R., and Resurreccion, A.V.A. 1993b. Optimization of sensory qualities of an extruded snack based on cornstarch and ization of sensory qualities of an extruded snack based

Prinyawiwatkul, W., McWatters, K.H., Beuchat, L.R., and Phillips, R.D. 1996b. Cowpea flour: a potential ingredient in food products. CRC. Crit. Rev. Food Sci. Nutr. 36: 413-436.

Prinyawiwatkul, W., McWatters, K.H., Beuchat, L.R., and Phillips, R.D. 1997. Physico-chemical and sensory properties of chicken nuggets extended with fermented cowpea and peanut flours. J. Agric. Food Chem. 45: $1891 \rightarrow 1899$.

Ray, F.K., Parrett, N.A., Van Stavern, B.D., and Ockerman, H.W. 1981. Effect of soy level and storage time on the quality characteristics of ground

beef patties. J. Food Sci. 46: $1662-1664$.
SAS Institute, Inc. 1988. SAS/STAT U' Users' Guide, version 6.03 ed. SAS Institute, Inc., Cary, NC. 


\section{SENSORY QUALITIES OF EXTENDED CHICKEN NUGGETS. . From page 893}

Scheffe', H. 1958. Experiments with mixtures. J. Royal Stat. Soc. B20: 344-360.

Schutz, H.G. 1983. Multiple regression approach to optimization. Food Technol. 37(11): $46-48,62$.

Sidel, J.L. and Stone, H. 1983. An introduction to optimization research. Food Technol. 37(11): 36-38. Sidel, J.L., Stone, H., and Thomas, H.A. 1994. Hitting the target: sensory

Torgersen, H. and Toledo, R.T. 1977. Physical properties of protein preparations related to their functional characteristics in comminuted meat systems. J. Food Sci. 42: 1615-1620, 1645.
Ms received 8/30/96; revised 1/11/97; accepted 1/23/97.

This study was supported in part by the Bean/Cowpea and Peanut Collaborative Research Support Programs (CRSP), U.S. Agency for International Development (AID).

We acknowledge Sue Ellen McCullough, Sandra O'Pry, Bob Flewellen, Glen Farrell, Lary Hitchcock, Kimberly Hortz, Yingxia Zhang, Anuvat Jangchud, and Kamolwan Suknark for technical assistance. 